\title{
Foreword: Pb-Free Solders and Emerging Interconnect and Packaging Technologies
}

The symposium "Pb-Free Solders and Emerging Interconnect and Packaging Technologies" was held during the 139th TMS Annual Meeting and Exhibition. This seven-session symposium provided an updated picture of research and development achievements in the field. The symposium covered the most important issues faced by researchers of Pb-free solder alloys: alloy development, electromigration, mechanical behavior, failure modes, intermetallics, whiskers, and reliability.

Alloying elements are still under intensive investigation for improving the performance of $\mathrm{Pb}$-free solders. Investigations of the microstructure of intermetallic compounds using stateof-the-art focused ion beam methodologies and in situ growth studies have provided new vision for microstructural research on Pb-free solders. The growth of whiskers and intermetallic compounds under the influence of electromigration remains of great interest and concern for $\mathrm{Pb}$-free solder applications.

This special issue is a collection of peer-reviewed articles presented at the symposium. It may not represent the full scope of the symposium, but it does offer a subset of very interesting work that was discussed. The organizing committee appreciates all the reviewers who assisted in improving the quality of the manuscripts. Assistance from the Editor-in-Chief, Professor Suzanne Mohney, during the review and publication process is also greatly appreciated.

Kwang-Lung Lin National Cheng Kung University

Sung K. Kang IBM T.J. Watson Research Center

Jenq-Gong Duh National Tsing-Hua University

Andre Lee Michigan State University

Thomas Bieler Michigan State University

Laura Turbini Research In Motion

Rajen Sidhu Intel Corporation

$\mathrm{Fu}$ Guo

Beijing University of Technology

Iver Anderson Ames Laboratory, Iowa State University

Guest Editors 